Keywords: Depressive disorders, Quality of care, Antidepressants, Treatment, Mental Health Services, Management, Psychiatry, Spain.

\title{
Current situation of depression healthcare in Spain: results of a psychiatrists' survey
}

\author{
Belén Martín-Águeda* \\ Francisco López-Muñoz* \\ Gabriel Rubio** \\ Pilar García-García* \\ Agustín Silva*** \\ Cecilio Álamo* \\ * Pharmacology Department, University of \\ Alcalá, Madrid \\ ** Retiro Mental Health Services, Madrid \\ *** Department of Health and Social-Medi- \\ cal Sciences, University of Alcalá, Madrid \\ SPAIN
}

\begin{abstract}
Objective: To analyze the current situation of healthcare for depression in Spain, according to psychiatrists opinion, and how it has evolved over the last 20 years, comparativily with the results reported in previous studies of our group.

Methods: Throughout 2002, we recorded the opinions of 101 specialists in psychiatry after asking them to fill out structured questionnaires in which they rated care, clinical, therapeutic and care quality.

Results: The presence of depressive disorders in healthcare is substantial, despite the high figures for "concealed epidemiology", with an increase in these last 20 years of disorders comorbid with anxiety. Currently, most patients arrive at the psychiatrist having been referred by their general practitioners (GP), as there is now less reluctance in depressive patients to such referral. In the last years there has been an increase in pharmacological treatment, with adverse effects of the drugs representing the major obstacle to nonadherence to such treatment. Selective serotonin reuptake inhibitors (SSRIs) constitute the pharmacological group of choice, and are the drugs most commonly used in the treatment of depression, together with venlafaxine. Areas where there is a need for improvement are time devoted to consultation, coordination between GPs and psychiatrists, waiting lists, and resources available to Mental Health Units.

Conclusions: Current situation of depression healthcare in Spain has substantially changed in recent years, improving in some aspects, thanks, in part, to the attitudes of GPs with this disorder and to evolution of pharmacological treatment.
\end{abstract}




\section{Introduction}

Depression constitutes the most prevalent psychiatric disorder in our society ${ }^{1}$. Epidemiological evidence suggests that its incidence is on the increase, and this evidence comes not only from studies in the community, but also from those of general medical practice, where an increase of three to ten times has been estimated, with a redistribution of prevalence by age and $\operatorname{sex}^{2}$.

According to the World Health Organization (WHO), some 121 million people are currently suffering from depression, with an annual prevalence of $5.8 \%$ for men and $9.5 \%$ for women ${ }^{3}$. However, these figures may vary according to the population studied and the criteria or diagnostic instruments used. A recent study carried out in 6 European countries ${ }^{4}$ found that prevalence over the life course was $12.8 \%$ in the case of major depression and 14\% for any depressive disorder $(9.5 \%$ in men and $18.2 \%$ in women).

In Spain, according to a study in the community ${ }^{5}$, weighted prevalence was estimated at $6.19 \%$, with differences between the sexes ( $4.5 \%$ in males and $7.8 \%$ in females). Likewise, it was estimated that $20 \%$ of patients in primary care may present a depressive disorder ${ }^{6,7}$.

Depression is a serious illness that substantially affects sufferers' lives and those of their families, and with high social, occupational and economic costs ${ }^{8,9}$. In 2001, the WHO, in their survey entitled "The Global Burden of Disease 2000 Study", examined the level of incapacity caused by different illnesses, using new epidemiological measures. Depression occupied fourth place in the ranking of incapacity; by the year 2020 it is expected to be in second place ${ }^{10}$.
Over the last 20 years there have been extremely positive developments with respect to health indicators in Spain, with a considerable increase in healthcare investment: per capita spending on the National Health Service increased six fold between 1984 and 2001 (Table I). As far as psychiatric care is concerned, the 1980s saw the introduction of a process of psychiatric reform, which has contributed to the improvement in mental health care in recent years. Nevertheless, not all the problems have been solved, and new needs have emerged in these 20 years ${ }^{11}$. Numbers of psychiatric hospitals and psychiatric hospital beds have fallen in this period, reflecting the phenomenon of deinstitutionalization that began in European countries in the 1970s (Table I). Such changes are an expression of the extension of outpatient mental health services and the attempt to modify the balance of care systems in favour of mental health units situated in the community and made up of specialized multidisciplinary teams, capable of providing effective support for primary care resources and dealing with the mental health problems of a sector of the population through these teams but in close collaboration with other specialist personnel.

On the other hand, the changes in the pharmacological tools available for the treatment of depression have been notable, above all since the clinical introduction of selective serotonin reuptake inhibitors (SSRIs) at the end of the 1980s, and later other antidepressants agents, such as venlafaxine, mirtazapine or reboxetine ${ }^{12,13}$.

It is the developments described above that have motivated the present study, whose objective was to analyze the current situation of healthcare for depression in Spain, in the opinion of psychiatrists, and study its evolution over the last twenty 
years, comparing the results reported with the obtained ones in previous studies of our group, designed with the same methodology 14,15,16: In the 1982 analysis, a total of 128 psychiatrists were interviewed using structured questionnaires, while in the study carried out in 1997, the number of interviewed psychiatrists was 300. In both cases, the samples were obtained from different cities and according to different health care professional characteristics.

Table I

Spanish National Health Indicators.

\begin{tabular}{|c|c|c|c|}
\hline Indicator & Year 1982 & Year 1997 & Year 2002 \\
\hline $\begin{array}{l}\text { National Health Care System expenditure/ } \\
\text { inhabitant }\end{array}$ & $179,5 \$(1984)^{\mathrm{a}}$ & $917 \$ \mathrm{e}$ & $1,148 \$(2001)^{\mathrm{e}}$ \\
\hline Public Health Care expenditure vs GNP (\%) & $4.8^{\mathrm{b}}$ & $5.4^{\mathrm{f}}$ & $5.4(2001)^{\mathrm{f}}$ \\
\hline $\begin{array}{l}\text { Public Health Care Centers } \\
\text { Health Care Centers } \\
\text { Consultation Offices } \\
\text { Outpatient Centers } \\
\text { Hospitals }\end{array}$ & $\begin{array}{l}710+238 \text { conc. }^{\mathrm{c}} \\
328^{\mathrm{c}} \\
172+172 \text { conc. }^{\mathrm{c}}\end{array}$ & $\begin{array}{l}1,707(1995)^{\mathrm{g}} \\
3,128(1995)^{\mathrm{g}} \\
206(1995)^{\mathrm{g}} \\
788^{12}\end{array}$ & $2,889^{\mathrm{k}}$ \\
\hline $\mathrm{N}^{\circ}$ inhabitants / physician & $362^{\mathrm{c}}$ & $236^{\mathrm{h}}$ & $229^{\mathrm{h}}$ \\
\hline Hospital beds / 1000 inhabitants & $5.0^{\mathrm{d}}$ & $4.2^{\mathrm{i}}$ & $4.2(2000)^{\mathrm{m}}$ \\
\hline $\begin{array}{l}\mathrm{N}^{\circ} \text { of Psychiatric hospitals } \\
\text { Public } \\
\text { Private (charity) } \\
\text { Private (no charity) }\end{array}$ & $\begin{array}{r}113^{\mathrm{d}} \\
52^{\mathrm{d}} \\
21^{\mathrm{d}} \\
40^{\mathrm{d}}\end{array}$ & $\begin{array}{l}87^{\mathrm{j}} \\
38^{\mathrm{j}} \\
21^{\mathrm{j}} \\
28^{\mathrm{j}}\end{array}$ & $\begin{array}{l}91^{1} \\
38^{1} \\
23^{1} \\
30^{1}\end{array}$ \\
\hline Psychiatric hospital beds & $37,725^{\mathrm{d}}$ & $19,194^{\mathrm{g}}$ & $15,605(2001)^{\mathrm{n}}$ \\
\hline
\end{tabular}

${ }^{\mathrm{a}}$ Spanish national health (INSALUD) data; ${ }^{\mathrm{b}}$ April report; ${ }^{\mathrm{c}}$ FARMAINDUSTRIA: Pharmaceutical Industry in figures, 1985; ${ }^{\mathrm{d}}$ INE: Year Statistical Report, $1986 ;{ }^{\mathrm{e}}$ OMS data, (www.who.int/country/esp/es); ${ }^{\mathrm{f}} \mathrm{MSC}$, Institute of Health Information, 2003; ${ }^{\mathrm{g}}$ MSC: Spanish Nacional Health. Data and figures, 1995; ${ }^{\mathrm{h}}$ Year Statistical Report (www.ine.es/inebase); ${ }^{i}$ Health Data Base for all, OMS European Regional Office (Health Systems under transition. Spain, 2001); ${ }^{\mathrm{j}}$ MSC data: Statistics of Health Centers, $1997 ;{ }^{\mathrm{k}}$ Institute of Heath Information, 2003; 1MSC, National Hospitals Catalogue 2003; ${ }^{\mathrm{m}}$ Year Statistical Report; Health Indicators, 2000; ${ }^{\mathrm{n}}$ MSC. National Hospitals Catalogue, 2001.

GNP: Gross Nacional Product.

\section{Methods}

Using structured questionnaires filled out by the participants themselves, the present study recorded the opinions of a sample randomized of 101 specialists in psychiatry (error margin of $\pm 10.0 \%$, for a confidence level of $95.5 \%$ ). These questionnaires consisted of 39 items dealing with aspects related to the care provided and its quality, as well as clinical and therapeutic aspects.
They also included, at the end, a section for sociodemographic and occupational data, such as age, sex, years in the profession, place of work, type of work and mean number of patients seen per day.

Participants were provided with assistance for the questionnaires from expert sociologist interviewers, who also distributed and collected them. The questionnaires were distributed randomly, throughout 2002, among psychiatrists in several 
cities, with the aim of guaranteeing maximum representativeness of the results. The questionnaires used in our study were designed following the lines of previous studies carried out by our team ${ }^{16}$, and applied in the social-health White Book "The quality of care for depression in Spain" $(n=300)^{15}$, so as to permit the comparison of our results with previous data. Likewise, some questions were designed with the aim of obtaining data to compare with the survey carried out in the sociological White Book “Depression in Spain" ( $n=$ $128)^{14}$, and to analyze the evolution of different parameters.

The statistical analysis of the data obtained in the present study was carried out using the SPSS program, version 11.5, and on some occasions the Statistix program, version 2.0. A descriptive analysis was made of the demographic and practicerelated data of the samples. The qualitative variables (sex, place of work, type of work) were presented in the form of percentages. The quantitative variables (age, number of patients seen per day) were described using mean and standard deviation. On comparing our results with those of previous studies we used the chi square test or, where appropriate, Fisher's exact test. For the quantitative variables we used the classic Student $t$ test for independent samples. Significance levels were set at $0.1 \%, 1 \%$ and $5 \%$, expressed by means of $p<0.001, p<0.01$ and $p<$ 0.05 , respectively.

\section{Results}

A total of 101 psychiatrists participated in this study, $51.1 \%$ of whom were male. Mean age was 41.1 years $( \pm 9.6)$, and they saw a mean of $12.5( \pm 4.9)$ patients per day.
Of these 101 participants, $81 \%$ worked in public clinics or hospitals, $6 \%$ in the private sector and $13 \%$ in both. Sixty-eight percent worked with outpatients, $16 \%$ in hospitals and $9 \%$ in both contexts. As regards experience, $27.3 \%$ had been working in the profession for less than 6 years, $30.3 \%$ for between 6 and 15 years, $34.3 \%$ for $16-30$ years and $8 \%$ for more than 30 years.

\section{Care aspects}

Of the total of actual depressive disorders in the population, the psychiatrists consider that only in $51.6 \%$ of cases is professional help sought. Nevertheless, the presence of depressive disorders in healthcare is substantial. Thus, the psychiatrists estimate that $75.6 \%$ of patients they see are depressive, with depression constituting the principal reason for the consultation in $81.2 \%$, while in $18.8 \%$ of cases it is detected in a secondary manner.

As regards the main routes through which depressive patients reach the psychiatrist's consulting room, in the majority of cases they were referred by general practitioners (GPs) $(58.0 \%$ ), while $14 \%$ consulted the psychiatrist directly, $10.9 \%$ became patients after emergency hospitalization, and the remainder arrived via other routes.

As far as the time the psychiatrists spend with their patients is concerned, in the first visit they invest a mean of 45.6 minutes, and in review visits, 23.7 minutes, the latter having decreased by 4 minutes ( $\mathrm{p}<$ 0.01 ) with respect to the 1997 figure. Mean frequency of review for depressive patients is every 24 days in the first stages of treatment, and around every two months in later phases. 
The main reasons for referral of depression cases by GPs, according to the psychiatrists, are "lack of response to treatment" $(55.7 \%)$ "risk of suicide" $(55.1 \%)$ and "severe depression" (44.39\%). Forty percent of the psychiatrists believe that the GP refers the patient in the majority of cases.

The level of communication and collaboration between primary and specialist care is rated quite positively by the psychiatrists in our study [mean of 3.3 on a scale of 1 (very poor) to 5 (very good)], despite the fact that the information on referral of depressive patients by GPs is considered no more than "barely satisfactory". Furthermore, on comparing this relationship with those they maintain with other specialists, the results are also positive [mean of 1.72 on a scale of 1 (better than with other specialists) to 3 (poorer than with other specialists)]. A total of $60 \%$ of the psychiatrists believe the aspect with most room for improvement in this relationship to be that of communication, followed by coordination between the two groups $(22.6 \%)$ and training standards of GPs $(15.5 \%)$.

\section{Clinical aspects}

Table II shows the importance of different life events and categories of person in the development of depression, with women (79\%) and "being divorced-separated" (74\%) as the most high-risk categories, in the opinion of the psychiatrists. Currently, more importance is given to this latter group (as is also the case for "death of family member", "health problems", "alcoholism" and "immigrants-marginalized people") than in 1997.

From the diagnostic point of view, "assessment of symptoms" and "patient interview" are the diagnostic instruments most commonly used by psychiatrists, according to the results of our study. Routine use of tools for diagnosis and the analysis of evolution of the disorder, including diagnostic questionnaires and psychometric scales, is scarce, as is the employment of other diagnostic tests (Figure 1). The commonest problem for detecting a depressive disorder in a consultation is "masking by other symptoms/disorders", according to $85 \%$ of the professionals in the survey (Figure 2).

Table II

Categories of individuals and life situations in relation to depression.

\begin{tabular}{lcc} 
& Year 2002 & Year 1997 \\
& $(\%)$ & 80.7 \\
\hline Females & 79 & $46.7^{*}$ \\
Divorced/separated patients & 74 & $36.7^{*}$ \\
Death of relatives & 61 & 47.3 \\
Elderly subjects & 48 & $26.0^{*}$ \\
Health problems & 46 & $24.7^{*}$ \\
Alcoholics & 41 & 27.3 \\
Low socio-economical status & 30 & $6.3^{*}$ \\
Emigrants & 23 & 13.3 \\
Drug addicts & 17 & 18.7 \\
Adolescents & 10 & 17.3 \\
Males & 10 & 2.3 \\
Labour conflicts & 6.5 & 6.0 \\
Children & 1 &
\end{tabular}

$* \mathrm{p}<0.001$ 


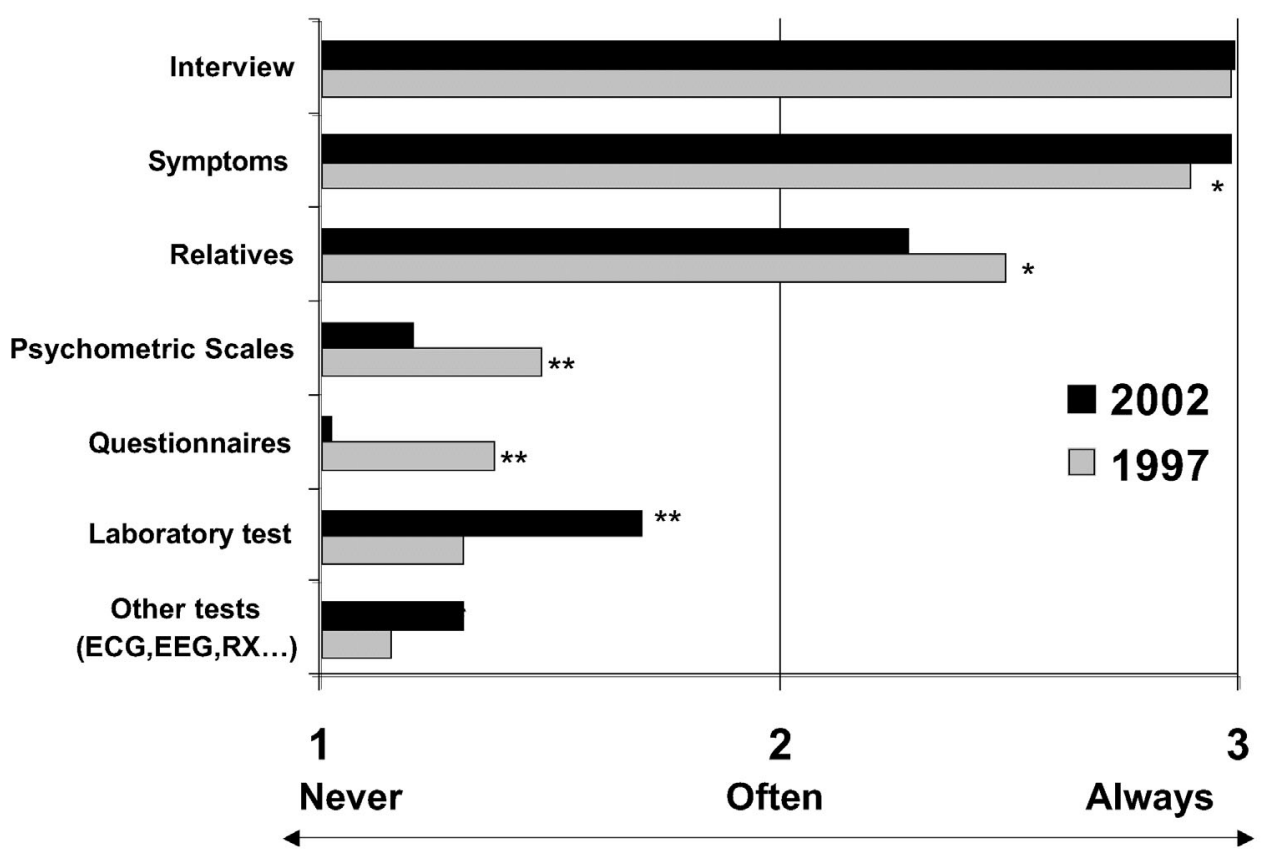

Figure 1. Frequency of diagnostic tools used. $* \mathrm{p}<0.05 ; * * \mathrm{p}<0.01$

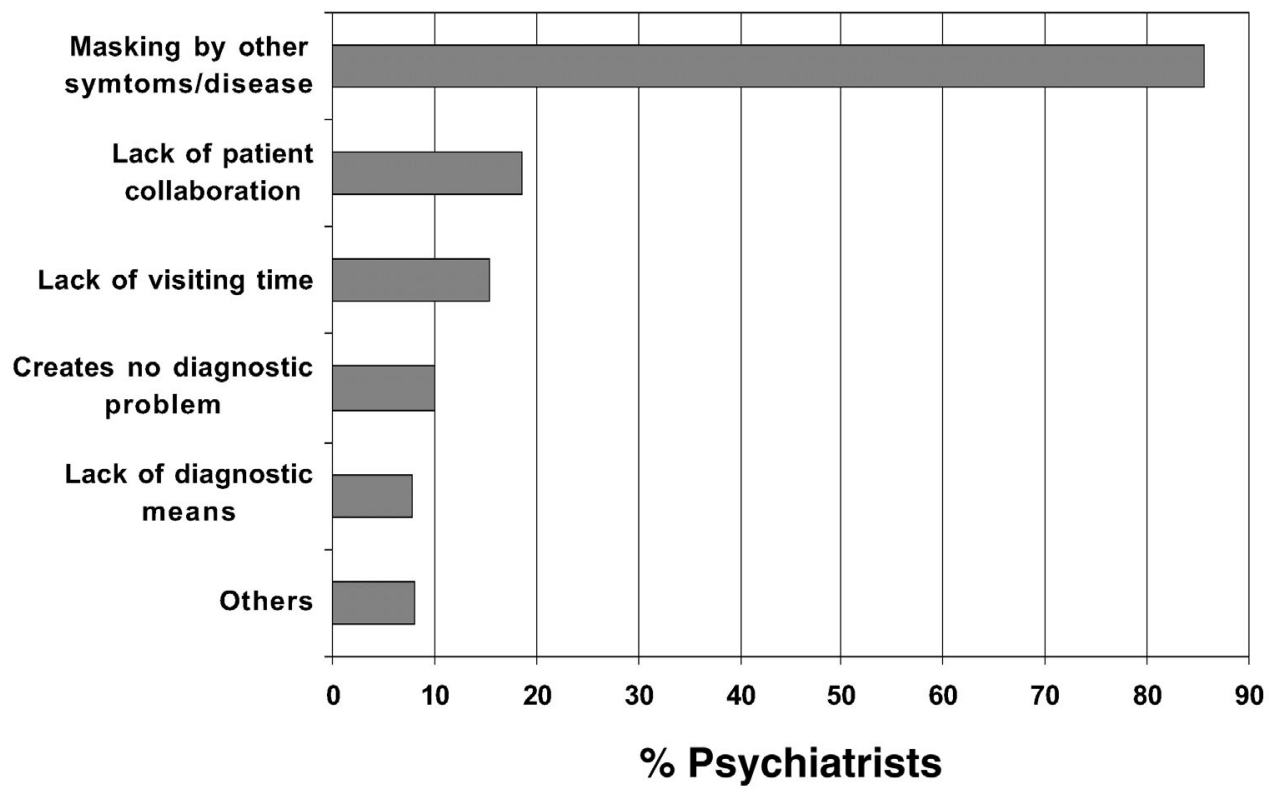

Figure 2. Most common problems for detecting depression. 
The depressive symptoms mainly used by these specialists in establishing a diagnosis are depressed mood (84.4\%), anhedonia $(70.8 \%)$, loss of vitality $(65.6 \%)$ and sleep disorders $(45.8 \%)$.

\section{Therapeutic aspects}

Practically all the psychiatrists in the study state that they used pharmacological treatment with all their depressive patients. Furthermore, over $70 \%$ use other therapeutic measures, such as psychotherapy, counselling or recommendation of healthy life habits, and $90 \%$ report speaking regularly to patients' families.
The drugs most commonly used by the psychiatrists in the treatment of depressive patients are SSRIs (96.9\%), serotonin-noradrenaline reuptake inhibitors (SNRIs) (venlafaxine) (84.4\%) and anxiolytics $(68.4 \%)$, with SSRIs as the first-choice category (Figure 3).

Level of adherence to pharmacological treatment is rated as highly favourable by $88 \%$ of the psychiatrists, though in the case of non-pharmacological treatments they estimate adherence levels as lower. The main reasons for lack of adherence to treatment are adverse effects (79.8\%), long duration $(46.5 \%)$, patients' belief that it is unnecessary $(40.4 \%)$ and lack of remission of symptoms (28.3\%) (Figure 4).

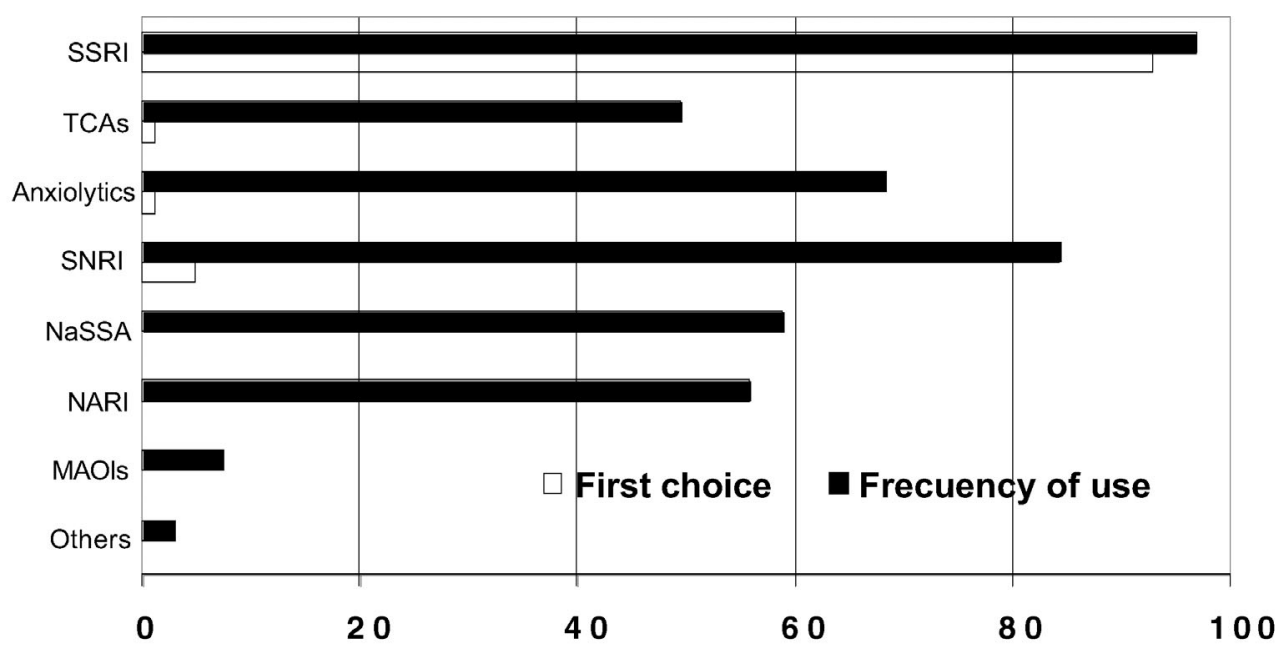

\section{\% Psychiatrists}

Figure 3. Frequency of drug use and first-line pharmacological treatments.

SSRI: Selective Serotonin Reuptake Inhibitors

TCAs: Tricyclic Antidepressants

SNRI: Serotonin and noradrenaline reuptake inhibitor (velafaxine)

NaSSA: Noradrenergic and Specific Serotonergic Antidepressants (mirtazapine)

NARI: Noradrenaline Reuptake Inhibitors (reboxetine)

MAOIs: Monoamine oxidase inhibitors 


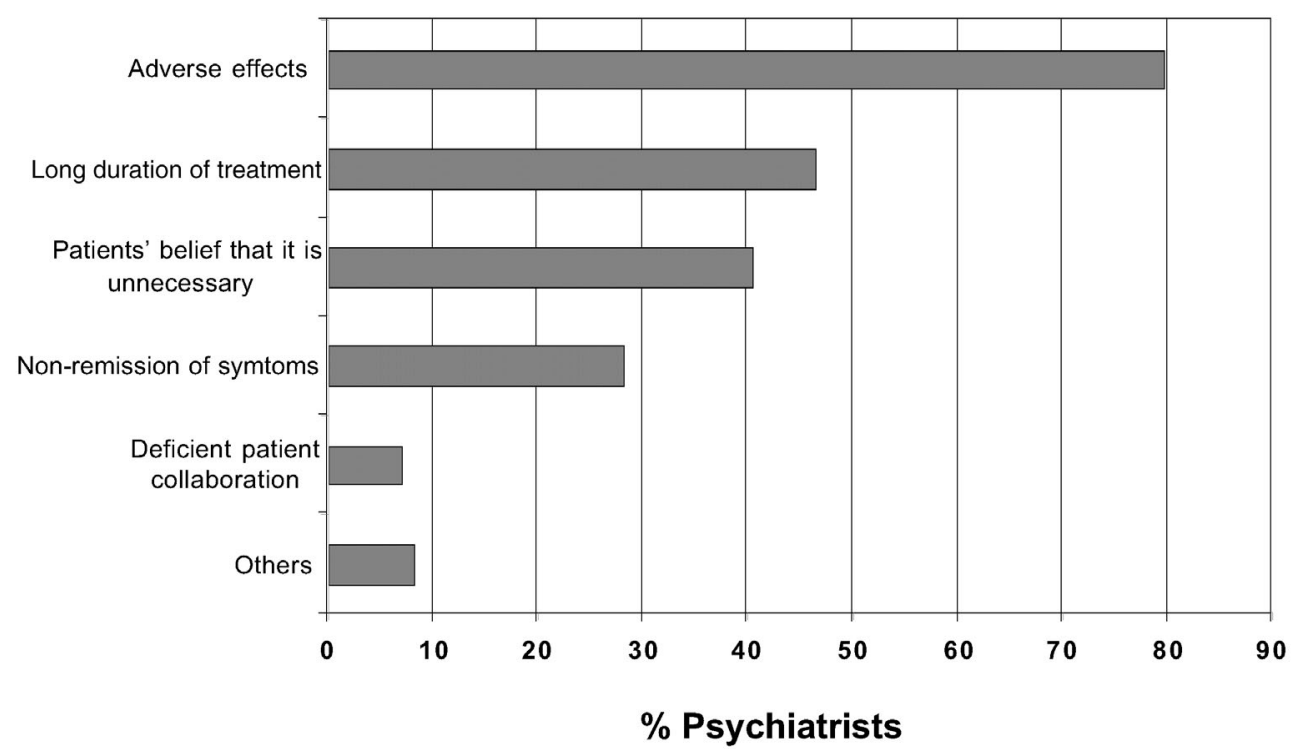

Figure 4. Reasons for lack of adherence to pharmacological treatment.

\section{Quality of care}

Quality of care for depression in Spain is rated positively by the psychiatrists [mean of 3.72 on a scale of 1 (very poor) to 5 (very good)]. Nevertheless, they consider the resources available in the primary care sector for the diagnosis $(46 \%)$ and treatment $(60 \%)$ of depression to be insufficient (Table III). As regards the factors that influence quality of care for depressive patients, on a scale of 1 (highly negative) to 5 (highly positive), "transfers and mobility of specialists" was considered the factor with the most negative influence (2.04), while "advances in pharmacological treatment" was considered to make the most positive contribution (4.1), followed by changes in the attitudes of GPs to depression (3.3).

Table III

Quality parameters in the management of depression.

\begin{tabular}{llccc} 
& $\begin{array}{c}2002 \\
(\%)\end{array}$ & $\begin{array}{c}1997 \\
(\%)\end{array}$ & $\begin{array}{c}1982 \\
(\%)\end{array}$ & $\mathrm{p}$ \\
\hline $\begin{array}{l}\text { Do GPs have sufficient means to diagnose depression? } \\
\begin{array}{l}\text { Can depressive patients be effectively treated in the } \\
\text { public psychiatric health care setting? }\end{array}\end{array}$ & 54.0 & 55.3 & - & $\mathrm{NS}$ \\
$\begin{array}{l}\text { Do GPs have sufficient means to correctly } \\
\text { treat depression? }\end{array}$ & 62.6 & 72.3 & $11.7^{*}$ & $\mathrm{p}<0.001$ \\
\hline
\end{tabular}

*significative difference between 1982 year versus 1997 and 2002 years 
The main aspects to be improved in healthcare for depression in Spain, according to the psychiatrists in this study [on a scale of 1 (much room for improvement) to 5 (less room for improvement)], would be consultation time (1.93), coordination between GPs and psychiatrists (1.99) and resources for Mental Health Units (1.99).

\section{Discussion}

The quality of healthcare for depression in Spain has changed in the last 20 years, improving in some aspects, as shown by the results of our study and the comparative analysis made with similar studies carried out previously ${ }^{14,15,16}$. However, a limitation exists that must be commented; the little sample of psychiatrists interviewed, in spite of its statistical representativeness, it can prevent, partly, the extrapolation of the conclusions to the majority of Spanish psychiatry.

There is confirmation of the central role of depressive disorders in healthcare, as our data show that depressive patients account for $75.6 \%$ of those who consult the psychiatrist, with depression as the principal reason for the consultation in the majority of cases.

The circumstances in which the patient arrives at the psychiatrist's consulting room have evolved positively over the last 20 years. Currently, most of the patients seen by psychiatrists have been referred by their GP, whilst in 1982, $87.5 \%$ of the psychiatrists reported that the majority of patients were referred to them by a friend, with only $44.5 \%$ having been sent by their $\mathrm{GP}^{16}$. These results reflect the sociocultural prejudices that persisted in the 1980s with regard to psychiatric help: the psychiatric patient, and therefore also the depressive patient, was subject to quite negative social consideration. Nowadays this stigma appears to have largely disappeared, with a notable improvement in the way psychiatric patients and care specialist are viewed, and the consideration of mental disorders as a pathology like any other ${ }^{17,18}$.

Time devoted to consultation is considered as the main aspect to be improved in healthcare for depression. Despite significant progress with regard to the 1982 figure, in which mean consultation time was less than 5 minutes, according to the professionals interviewed, the time invested by psychiatrists in review consultations has decreased since 1997. This reduction in consultation time in recent years is probably related to an increase in psychiatrists' workload in this same period.

The personal category with most relevance in depression is female sex, as shown in various studies ${ }^{19,20}$. Other categories that have acquired greater significance in recent years, as regards their influence in the development of depression, are "being divorced-separated", "death of a family member", "health problems", "dependence on alcohol" and "being an immigrant/marginalized person". As far as the "divorcedseparated" condition is concerned, some authors ${ }^{7}$ have found it to be associated with greater consumption of antidepressants. Furthermore, it has been suggested that immigrants present higher rates of depression and anxiety disorders than groups with identical sociodemographic characteristics from their country of origin or from the host culture $^{21}$. The principal reasons for this situation could be found in processes of adaptation and contextual difficulties associated with emigration. Moreover, the psychological problems of immigrants are more likely to express themselves in the form of somatic symptoms ${ }^{22}$. 
An important aspect in the process of referral by GPs to specialists is the information back-up for this referral and the perceived quality of such back-up. This data support is considered as barely satisfactory by psychiatrists, with no improvement in this perception in recent years, despite the fact that the proportion of GPS who stated that they referred patients together with a report rose from $61.1 \%$ in 1997 to $85 \%$ in 2002. What undoubtedly explains psychiatrists' lack of satisfaction is their interest, more than in whether or not the report is sent, in its quality: in their view, what is basically lacking are clinical history data and an improvement in the report itself. However, time pressure, combined with a lack of specialist training and background in GPs, often continue to affect the adequacy of referral reports.

As regards the relationship between the two levels of care, communication, coordination and training of GPs are the aspects where there is considered most room for improvement. These data coincide with the results of a survey carried out on psychiatrists and GPs in Montreal, according to whom improved communication and continuing medical education for GPs in the field of psychiatry would be the principal options for more effective collaboration between the two healthcare levels ${ }^{23}$.

Anxiety states were mentioned, as clinical manifestations of depression in patients, by only $5 \%$ of the professionals interviewed in 1982 , a figure that had risen to $38.0 \%$ by the time of the present study. This reflects the association between depressive disorders and anxiety conditions described in numerous studies carried out with large samples that yielded figures similar to or even more conclusive than those obtained in our research. Thus, in the DEPRES II study, Tylee ${ }^{24}$ observed a comorbidity of depressive disor- ders and anxiety of 57\%. Similar results were obtained in the "US National Comorbidity Survey" $(51 \%)^{25}$, in the "WHO Collaborative Study" $(40 \%)^{26}$ and in the "US Medical Outcomes Study" $(54 \%)^{27}$. Given the high prevalence of comorbidity of depression and anxiety, it is important for professionals to detect this type of patient so as to select the most appropriate therapeutic tool, since such depressive conditions have been associated with greater severity, longer duration and higher risk of suicide ${ }^{28,29}$.

From the diagnostic perspective, "assessment of symptoms" and "patient interview" are the diagnostic instruments most commonly used by the psychiatrists, scarce few of whom routinely use diagnostic questionnaires or psychometric scales. Our results are in line with those of the study carried out by Depont et al. ${ }^{30}$ in a sample of French psychiatrists, in which $79.3 \%$ reported making diagnoses according to "clinical judgement", and very few stated that they used scales or diagnostic instruments.

Better clinical knowledge of depression, and of the tools for its diagnosis, may help to explain the fact that the percentage of physicians who report that the diagnosis of depression causes them no problem has fallen over the last 20 years. Thus, in 1982, almost 50\% of the psychiatrists interviewed claimed they had no problem for diagnosing depression, while the current figure for those who say they never have any problem detecting a depressive disorder in their patients is just $10 \%$. Indeed, in 1982, it was "lack of specialist training" that was the main problem for the diagnosis of depression, while today it is "masking by other symptoms".

The psychiatrists interviewed in the present study report that the drugs they use most in the treatment of depressive patients are SSRIs and SNRIs (venlafaxine). By compar- 
ison with the situation in 1997, there is a notable increase in the use of venlafaxine and a decrease in the use of tricyclic antidepressants and other groups, such as reversible and selective monoamine oxidase inhibitors (MAOIs) and second-generation antidepressants. The introduction onto the market of SSRIs, and subsequent pharmacological developments, have had a substantial influence on the increase in the consumption of antidepressants, as well as on changes in the pattern of their use $\mathrm{e}^{31,32}$.

Ninety percent of the psychiatrists report SSRIs as their first-choice antidepressant, as against 50\% in 1997. In a 1995 study with French psychiatrists it was found that the majority chose SSRIs above all others, and $59 \%$ claimed to use them routinely ${ }^{33}$. In this regard, while the indicators of effectiveness and time necessary for obtaining an antidepressant response are similar for SSRIs and tricyclic antidepressants - this having been demonstrated in several meta-analyses of clinical trials ${ }^{34,35}$-, SSRIs have certain advantages, such as ease of use, anxiolytic capacity and more acceptable tolerance and safety profiles ${ }^{13,36,37,38,39}$.

In general terms, the psychiatrists consider the quality of healthcare for depression in Spain to be good, though despite a significant improvement over the past 20 years, there is clearly room for more. Up to 1997 , the most pressing need in the view of psychiatrists was the improvement of training for GPs, but currently, there are other concerns that are considered more important, such as time devoted to consultations, coordination between GPs and psychiatrists, and provision of resources for Mental Health Units. In relation to these aspects, Katon et al. ${ }^{40}$ found that more thorough therapeutic intervention than normal (close collaboration between psychiatry and primary care staff, intensive education for the patient and supervision of adherence to treat- ment) not only improves patients' adherence to antidepressive treatment, but also results in their recognizing the better quality of care.

For their part, López-Ibor et al. ${ }^{41}$ consider that continuing training of GPs, together with the provision of more resources, permitting longer consultation times and the promotion of fluid communication between the two care levels, are the main aspects to be improved in depression healthcare in Spain.

\section{Conclusions}

The healthcare management to depression in Spain has changed considerably in the last 20 years, improving in some aspects, as shown by the results of our study, thanks, in part, to changes in the attitudes of GPs to this disorder. Moreover, there has been an important change in relation to the therapeutic management of the depressive patient, with an increase in recourse to pharmacological treatment, which is better adhered to than other types of therapeutic programme. Venlafaxine and SSRIs are the drugs most commonly used by psychiatrists interviewed in the treatment of depression, the latter being the first-choice type of drug. The main areas for improvement in healthcare in Spain, according to the specialists in this study, are consultation time, coordination between GPs and psychiatrists, waiting lists, and resources available to Mental Health Units.

\section{References}

1. Ayuso JL. Concepto y clasificación. Aspectos epidemiológicos y significado socioeconómico de la depresión. Salud Rural 1999; 3: 107-109. 
2. Murphy JM, Laird NM, Monson RR, Sobol AM, Leighton AH. A 40-year perspective on the prevalence of depression: the Stirling County Study. Arch Gen Psychiatry 2000; $57: 209-215$.

3. World Health Organization. Mental and neurological disorders. Fact sheet $\mathrm{N}^{\circ} 265 ;$ 2001. Available at: www.who.int/mediacentre.

4. ESEMeD/MHEDEA 2000. Prevalence of mental disorders in Europe: results from the European Study of the Epidemiology of Mental Disorders (ESEMeD) project. Acta Psychiatr Scand 2004; 420: 21-27.

5. Vázquez Barquero J, Díez Manrique J, Pena C, Aldama J, Samaniego Rodríguez C, Menendez Arango J et al. A community mental health survey in Cantabria: a general description of morbidity. Psychol Med 1987; 17: 227241.

6. De La Gándara J. Manejo de depresión y ansiedad en atención primaria. Aten Primaria 1997; 20: 389-394.

7. Rispau A, Soler M, García I, Caramés E, Espín A, García C. Factores de riesgo asociados al consumo de antidepresivos. Aten Primaria 1998; 22: 440-443.

8. Jonson B, Rosenbaum J. Economía de la Salud en la depresión. Chichester: John Wiley \& sons; 1995.

9. Sáiz J, Ibáñez A. Tratamiento de los trastornos depresivos. Rev Clin Esp 1997; 197: 35-43.

10. Üstün TB, Ayuso-Mateos JL, Chatteerji S, Mathers C. Global burden of depressive disorders in the year 2000 . Br J Psychiatry 2004; 184: 386-392.

11. Giner J. La reforma psiquiátrica permanente. In: López-Ibor J, Gómez Pérez J, Gutiérrez Fuentes JA. (Eds). Retos para la Psiquiatría y la Salud Mental en España. Barcelona: Psiquiatría Editores S.L.; 2003. p. 3-11.

12. Alonso MP, De Abajo FJ, Martínez JJ, Montero D, Martín-Serrano G, Madurga M. Evolución del consumo de antidepresivos en España. Impacto de los inhibidores selectivos de la recaptación de serotonina. Med Clin 1997; 108: 161-166.

13. Pirraglia PA, Stafford RS, Singe DE. Trends in prescribing of selective serotonin reuptake inhibitors and other newer antidepressant agents in adult primary care. Prim Care Companion J Clin Psychiatry 2003; 5: 153-157.

14. Gabinete de estudios sociológicos Bernard Krief. Estudio sociológico Libro Blanco "La depresión en España”. Madrid: Bernard Krief; 1982

15. Gabinete de estudios sociológicos Bernard Krief. Estudio sociosanitario Libro Blanco "La calidad asistencial de la depresión en España". Madrid: Bernard Krief; 1997.

16. López-Ibor JJ, Alamo C, López-Muñoz F, Cuenca E, Rubio G, Otero FJ. Evolution of the management of depression in Spain from the psychiatrist's perspective. A comparative analysis: 1997 versus 1982. Eur Psychiatry 2000; 15: 362-369.

17. Paykel ES, Hart D, Priest RG. Changes in public attitudes to depression during the defeat depression campaign. Br J Psychiatry 1998; 173: 519-522.

18. Goldstein B, Rosselli F. Etiological paradigms of depression: The relationship between perceived causes, empowerment, treatment preferences, and stigma. J Ment Health 2003; 12: 551-563.

19. Aragonés E, Gutiérrez M, Pino M, Lucena C, Cervera J, Garreta I. Prevalencia y características de la depresión mayor y la distimia en atención primaria. Aten Primaria 2001; 27: 623-628.

20. Gabarrón E, Vidal JM, Haro JM, Boix I, Jover A, Arenas M. Prevalencia y detección de los trastornos depresivos en atención primaria. Aten Primaria 2002; 29: 329337.

21. Ekblad S, Kohn R, Jansson B. Psychological and clinical aspects of immigration and mental health. In: Okpaku SO, (Eds). Clinical methods in transcultural psychiatry. Washington: American Psychiatric Press; 1998.

22. García Campayo J, Alda Díez M. Problemas derivados de la inmigración. In: López-Ibor J, Gómez Pérez J, Gutiérrez Fuentes JA, Eds. Retos para la Psiquiatría y la Salud Mental en España. Barcelona: Psiquiatría Editores SL; 2003. p. 259-277.

23. Lucena R, Lesage A, Élie R, Lamontagne Y, Corbiére M. Strategies of Collaboration Between General Practitioners and Psychiatrists: A survey of Practitioners' opinions and Characteristics. Can J Psychiatry 2002; 47: 750-758.

24. Tylee A, Gastpar M, Lepine JP, Mendlewick J. DEPRES II (Depression Research in European Society II): a patient survey of the symptoms, disability and current management of depression in the community. Int Clin Psychopharmacol 1999; 14: 139-151.

25. Kessler RC, McGonagle KA, Zhao S, Nelson CB, Hughes M, Eshleman S et al. Lifetime and 12-month prevalence of DSM-III-R psychiatric disorders in the United States. Results from The National Comorbidity Survey. Arch Gen Psychiatry 1994; 51: 8-19.

26. Sherbourne CD, Jackson CA, Meredith LS, Camp MA, Wells B. Prevalence of comorbid anxiety disorders in primary care outpatients. Arch Fam Med 1996; 5: 27-34.

27. Lecrubier Y, Üstün TB. Panic and depression: a worldwide primary care perspective. Int Clin Psychopharmacol 1998; 13 (Suppl 4): S7-S11. 
28. Fawcett J. Predictors of early suicide: identification and appropriate intervention. J Clin Psychiatry 1988; 49: $7-8$.

29. Brendan C. Recognition and Treatment of Depression in a Primary Care Setting. J Clin Psychiatry 1994; 55 (Suppl 12): 18-34.

30. Depont F, Rambelomanana S, Le Puil S, Begaud B, Verdoux H, Moore N. Antidepressants: Psychiatrists' opinions and clinical practice. Acta Psychiatr Scand 2003; 108: 24-31.

31. Rosholm JU, Gram LF, Isacsson G, Hallas J, Bergman U. Changes in the pattern of antidepressant use upon the introduction of the new antidepressants: a prescription database study. Eur J Clin Pharmacol 1997; 52: 205-209.

32. Stafford RS, MacDonald E, Finkelstein SN. National Patterns of Medication Treatment for Depression, 1987 to 2001. Prim Care Companion J Clin Psychiatry 2001; 3 : 232-235.

33. Laperey-Mestre M, Desboeuf K, Aptel I, Chale JJ, Montastruc JL. A comparative Survey of Antidepressant Drug Prescribing Habits of General Practitioners and Psychiatrists. Clin Drug Investig 1998; 16: 53-61.

34. Anderson IM, Tomenson BM. The efficacy of selective serotonin re-uptake inhibitors in depression: a metaanalysis of studies against tricyclic antidepressants. J Psychopharmacol 1994; 8: 238-249.

35. Menting JE, Honing A, Verhet FR, Hartmans M, Rozendaal N, de Vet HC et al. Selective serotonin reuptake inhibitors (SSRIs) in the treatment of elderly depressed patients: a quantitative analysis of the literature on their efficacy and side effects. Int Clin Psychopharmacol 1996; 11: 165-175.
36. Henry JA, Alexander CA, Sener EK. Relative mortality from overdose of antidepressants. Br Med J 1995; 310: 221-224.

37. Möller HJ, Volz HP. Drug treatment of depression in the 1990's. An overview of achievements and future possibilities. Drugs 1996; 52: 625-638.

38. López-Muñoz F, Alamo C, Cuenca E, Rubio G. Efecto de los fármacos antidepresivos sobre los isoenzimas del citocromo P-450 y su trascendencia clínica: perfil diferencial. Actas Luso Esp Neurol Psiquiatr 1997; 25: 397-409.

39. Álamo C, López-Muñoz F, Cuenca E. Gli SSRI nella pratica clinica a la loro validitá risppetto agli antidepressivi triciclici. Psichiatria \& Medicina 1997; I: 2.

40. Katon W, Von Korff M, Lin E, Walker E, Simon GE, Bush $\mathrm{T}$ et al. Collaborative management to achieve treatment guidelines: impact on depression in primary care. $\mathrm{J}$ Am Med Assoc 1995; 273: 1026-1031.

41. López-Ibor JJ, Alamo C, López-Muñoz F, Cuenca E, Rubio G, Otero FJ. A comparative analysis of depression management in primary care practice in Spain: 1997 versus 1982. Prim Care Psychiatr 1999; 5: 133-145.

Address for correspondence:

Dr. Francisco López-Muñoz

Pharmacology Department

University of Alcalá

C/ Juan Ignacio Luca de Tena, 8, 28027 Madrid, Spain

Telephone: +34 917248210

Fax: +34 917248229

E-mail: frlopez@juste.net

SPAIN 